\title{
Transformation of fibroblast-like synoviocytes in rheumatoid arthritis; from a friend to foe
}

\author{
Mohammad Javad Mousavi ${ }^{1,2,3}$, Jafar Karami i,4,5, Saeed Aslani ${ }^{2}$, Mohammad Naghi Tahmasebi ${ }^{6}$, \\ Arash Sharafat Vaziri ${ }^{6}$, Ahmadreza Jamshidi ${ }^{1}$, Elham Farhadi ${ }^{1,7^{*}}$ and Mahdi Mahmoudi ${ }^{1,7^{*}}$ (B)
}

\begin{abstract}
Swelling and the progressive destruction of articular cartilage are major characteristics of rheumatoid arthritis (RA), a systemic autoimmune disease that directly affects the synovial joints and often causes severe disability in the affected positions. Recent studies have shown that type B synoviocytes, which are also called fibroblast-like synoviocytes (FLSs), as the most commonly and chiefly resident cells, play a crucial role in early-onset and disease progression by producing various mediators. During the pathogenesis of RA, the FLSs' phenotype is altered, and represent invasive behavior similar to that observed in tumor conditions. Modified and stressful microenvironment by FLSs leads to the recruitment of other immune cells and, eventually, pannus formation. The origins of this cancerous phenotype stem fundamentally from the significant metabolic changes in glucose, lipids, and oxygen metabolism pathways. Moreover, the genetic abnormalities and epigenetic alterations have recently been implicated in cancer-like behaviors of RA FLSs. In this review, we will focus on the mechanisms underlying the transformation of FLSs to a cancer-like phenotype during RA. A comprehensive understanding of these mechanisms may lead to devising more effective and targeted treatment strategies.
\end{abstract}

Keywords: Cancer-like behavior, Rheumatoid arthritis, Fibroblast-like synoviocyte, Genetics, Epigenetics

\section{Background}

Rheumatoid arthritis (RA) is a complex, systemic, and chronic autoimmune disorder that is recognized as the most common inflammatory arthropathy worldwide [1]. Although the disease can occur in all individuals and all age ranges, the prevalence is highest among women over 40 years. The hallmark of the disease is a chronic inflammation of the joints that is characterized by synovial membrane hypertrophy, hyperplasia, and symmetrical polyarthritis. The inflammation may destroy cartilage,

\footnotetext{
*Correspondence: farhadie@tums.ac.ir; mahmoudim@tums.ac.ir

${ }^{1}$ Rheumatology Research Center, Tehran University of Medical Sciences, Tehran, Iran

${ }^{7}$ Inflammation Research Center, Tehran University of Medical Sciences, Tehran, Iran

Full list of author information is available at the end of the article
}

bone, and formation of extra-articular manifestations (EAMs) [2], which ultimately leads to limitations, disabilities, loss of function [2,3], loss of quality of life [4], and increased morbidity and mortality [5]. Similar to most autoimmune diseases, RA is also a multifactorial disease. Based on studies on genetic predisposition in twins and families, the overall risk associated with genetic factors and heritability of RA is about 50-60\% [6, 7]. Besides, cigarette smoking is the most important environmental factor involved in the disease onset, especially in people with a predisposing genetic background [8].

Specific fibroblasts located in the synovial membrane of the joints are referred to as synovial fibroblasts (SFs) or fibroblast-like synoviocytes (FLSs) $[9,10]$, which is also referred as B-type synoviocytes versus A-type synoviocytes (macrophage-like 
synoviocytes; MLSs). In recent years, FLSs have been introduced as the key players in the RA synovium [9, $11]$. FLSs are considered as the main source of cartilage degradation factors and inflammation [11]. In a normal physiological state, FLSs play an essential role in the homeostasis of the joints. Moreover, they play a chief role in releasing necessary synovial fluid components. Conversely, in activated state and joint inflammatory conditions, FLSs lose their contact inhibition potential, alongside with high proliferation, reduced apoptosis, and increased expression of cytokines and chemokines, adhesions molecules, and matrix metalloproteinases (MMPs), which contribute to pannus formation as a critical player $[10,12]$. Synovial hyperplasia is frequently seen in RA synovium, which results from the accumulation of FLSs and MLSs in a specific inflammatory microenvironment [12-14]. RA FLSs display cancerous properties in inflamed synovial tissue, whereby they exhibit local tumor-like destructive and invasive characteristics $[15,16]$. The phenotype, behavior, and role of FLSs in RA resemble the fundamental role of cancer-associated fibroblasts (CAFs) in various cancers $[17,18]$. In this article, we aimed to review the FLS transformation in RA, tumor-like behaviors of RA FLSs, and discuss the underlying mechanisms in three principal axes of metabolism, genetics, and epigenetic modifications (Fig. 1).

\section{FLSs and RA pathogenesis}

FLSs are mesenchymal origin cells and particularly found in the synovium lining membrane, that exhibit many features in common with fibroblasts, such as the expression of type IV and V collagens, and vimentin. On the other side, these cells also express specific surface markers, including Thy-1 membrane glycoprotein (CD90), decayaccelerating factor (DAF; CD55) and secrete unique proteins, like lubricin and hyaluronic acid [synthesized by UDP-glucose 6-dehydrogenase (UDPGDH)] [9, 10]. Concerning cell adhesion, FLSs express vascular cell adhesion molecule-1 (VCAM-1) and cadherin-11 [19]. Cadherin-11, one of the major FLS markers, play a key role in activating and regulating the function of FLSs in addition to cell adhesion [20]. The concept that FLSs destroy the cartilage and supporting structures of the joint is supported by data in cadherin-11 knockout mice, in which the animal lacks an intimal lining, regardless of normal development. Despite an inflammatory state as well as the progression of bone destruction, these synoviocyte-deficient mice do not present arthritis-induced cartilage damage [21].

The intimal lining of the RA synovium displays remarkable changes, with a marked increase in cellular content, and the lining membrane of the RA synovium expands 10-20-fold FLSs [22]. MLSs in RA synovium display a highly activated phenotype and produce pro-inflammatory

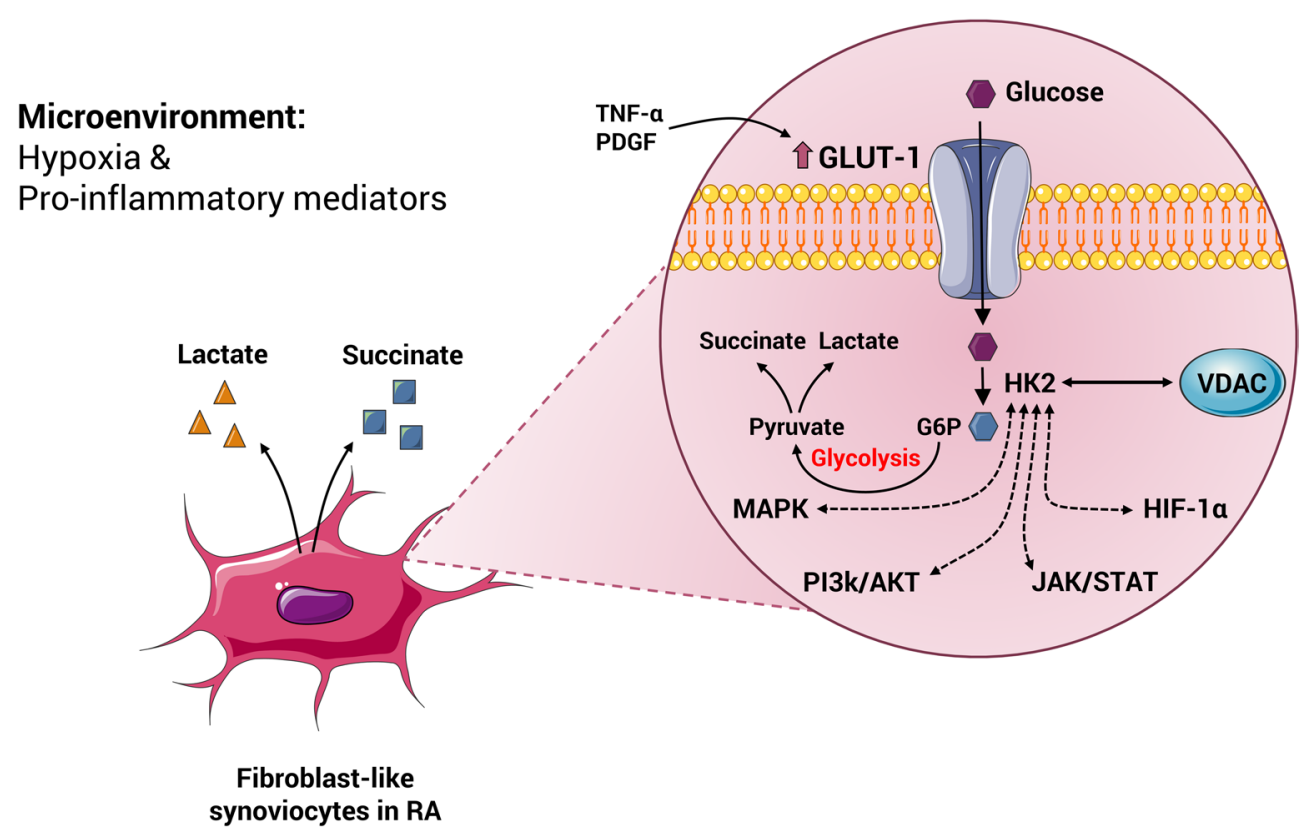

Fig. 1 Three main axes of tumor-like behaviors of RA FLSs; metabolism, genetics and epigenetics modifications 
cytokines, chemokines, and growth factors. These products can activate local FLSs in the lining and induce them to produce their mediators, especially interleukin (IL)-6, prostanoids, and MMPs. This process establishes a paracrine/autocrine network that leads to synovitis, recruitment of further immune cells to the joint, and contribution to the destruction of the extracellular matrix. Among these, interactions between FLSs and synovial $\mathrm{T}$ lymphocytes have been reported strongly in vitro and in vivo [23, 24]. T lymphocytes, even in the resting state, have the ability to activate the FLSs and stimulate the production and secretion of inflammatory mediators such as IL-6, IL-8, and prostaglandin E2 (PGE2) from them [25]. On the other hand, FLSs can also play an effective role in activating, presenting super antigens and proliferative stimulation to $\mathrm{T}$ lymphocytes [26].

The hypertrophied synovial tissue, called 'pannus' at the cartilage-bone interface, masks the cartilage and erodes it towards the bone. The pannus, which is composed of macrophages, osteoclasts, and invasive FLSs with relatively few lymphocytes, behaves like a locally invasive tumor [27]. With regards to FLSs' aggressive properties, hyperplasia, and production of vast amounts of proteases, these cells act as primary players in bone and cartilage destruction in the inflamed joints [22].

\section{The transformed phenotype of RA FLSs}

During RA development, the phenotype of RA FLSs is altered to an invasive and aggressive form, with increased migration ability and reduced attachment-dependent growth, leading to intimal lining layer hyperplasia and the articular cartilage destruction and, ultimately, pannus formation $[9,10]$. Transformed FLSs in the inflammatory microenvironment of the RA synovium are not just "passive responders", but as "imprinted aggressors" can continue to change their behaviors and phenotype, independently of external stimulation of the existing toxic and inflamed milieu $[10,28]$. It appears that FLSs are inherently and permanently transformed, similar to the transformation of cancer cells. In this regard, it has been shown that this transformed phenotype of RA FLSs persists upon transplantation to severe combined immunodeficiency (SCID) mouse model and this engraftment culminated in articular cartilage modulation through extracellular matrix destruction. Nonetheless, this behavior has not been observed in FLSs isolated from healthy subjects or even cases with osteoarthritis (OA) [29]. Significant differences in FLSs differentiation, proliferation, and adhesion are involved in divergences in the patterns and signature of DNA methylation in FLSs isolated from early RA individuals compared to that of patients with established RA [30]. Remarkably, studies that illustrate the role of FLSs in synovitis transition from an affected to a non-affected joint remind a process known as "metastasis", an important characteristic of cancerous cells pathogenesis [29, 31, 32].

\section{Cell metabolism in the transformed RA FLSs}

One of the main metabolic hallmarks in RA patients is a significant increase in "calorie consumption" which resulted in increased heat in the involved joint. Following extensive studies to detect metabolic and mitochondrial changes in tumor cells of various malignancies, studies on the metabolic changes of immune cells, stromal cells, and fibroblasts in dysregulated and inflammatory conditions have been performed [33-37]. Daily intake of energy increases in RA as it has been reported an $8 \%$ higher basal metabolic rate (BMR) in non-smoker RA patients compared to healthy subjects (this increase was even $20 \%$ in smoker RA subjects) [38]. Increased disability, decreased quality of life, and early mortality of RA patients have also been attributed to the increased metabolism rate [39].

In the transformed FLSs, metabolism of the four main classes of macromolecules (carbohydrates, lipids, proteins, and nucleic acids) changes, conferring an invasive potential to these cells [40,41]. In general, glucose metabolism (i.e., glycolysis and pentose phosphate pathway), tricarboxylic acid (TCA) cycle, and amino acid metabolisms, such as tyrosine-derived catecholamine and protein biosynthesis, in RA FLSs are severely impaired even compared to OA FLSs [42-44]. Investigation of the metabolic profile of RA synovial tissue has shown the main shift toward glucose and choline metabolism in RA FLSs [45-47].

Elevated glucose metabolism is one of the main characteristics of the active and proliferating cells, similar to tumor cells. Increased metabolism of glucose and glycolysis process provides the required amounts of metabolic mediators to support the anabolic processes of lipids, nucleic acids, and proteins in proliferating RA FLSs [48]. Upregulated glucose metabolism in RA FLSs can contribute to inflammation and joint damage. In addition to overexpression of glucose transporter 1 (GLUT1) and glucose uptake in RA FLSs, tumor necrosis factor- $\alpha$ (TNF- $\alpha)$ and platelet-derived growth factor (PDGF) induce the GLUT1 mRNA expression and glucose metabolism. On the other hand, glucose deprivation or inhibition of glycolysis by glycolytic inhibitors such as bromopyruvate ( $\mathrm{BrPa})$, disrupts the proliferation, migration, and cytokine secretion of RA FLSs. Additionally, in vivo experiments have established that inhibition of glycolysis strongly reduced the severity of arthritis [44]. Elevated chronic glucose metabolism due to hypoxia and highly pro-inflammatory mediators 
in the microenvironment of the RA synovium, stimulates and activates important signaling pathways in FLSs, including mitogen-activated protein kinase (MAPK), phosphatidylinositol-3-kinase (PI3K)/Akt, Janus kinase (JAK)/STAT, and hypoxia-inducible factor (HIF)-1 $\alpha$ [49]. Eventually, upregulated glucose metabolism in inflammatory conditions and arthritis-like RA resulted in increased serum lactate and succinate [50, 51] (Fig. 2).

Raised levels of choline kinase (CK)- $\alpha$ (also known as choline phosphokinase), the primary enzyme of the choline pathway and phosphatidylcholine synthesis, has been shown to play a fundamental role in cell transformation, invasion, and metastasis in various cancers [52-54]. CK is highly expressed in the RA synovial tissue and cultured RA FLSs. So, CK inhibitors inhibit invasive properties, including cell migration and resistance to apoptosis of FLSs in vivo, as well as a deceleration of arthritis development and amelioration of arthritis symptoms [47].

It has been documented that hypoxia can promote a switch to glycolysis, supporting abnormal angiogenesis, cellular invasion, and pannus formation [55]. In addition, glycolytic metabolites, including succinate [56], $\alpha$-ketoglutarate, fumarate, and acetyl-CoA, are involved in changes in epigenetics and cell signaling [57]. Furthermore, the accumulation of metabolic intermediates in FLSs under stress and hypoxic conditions contributes to anabolic mechanisms of nucleic acids, lipids, and proteins [41]. Interestingly, it has been reported that as RA progresses due to impairment in the lipids and glucose metabolism, the patients might be susceptible to the co-occurrence of cardiovascular diseases (CVD) and metabolic syndrome [58].

\section{Hyperplasia and resistance to apoptosis in RA FLSs}

Increased proliferation of RA FLSs is one of the causes of RA synovial hyperplasia [59]. However, expression of proto-oncogenes, such as c-myc in FLSs, lack of mitosis as well as immunohistochemistry (IHC) staining for some markers of nuclear division, suggests that cell division may not be the leading cause of synovial hyperplasia [41]. The limited number of mitotic divisions, the expression of Ki-67 as cell cycle marker, or the expression of proliferating cell nuclear antigen (PCNA), all suggest that DNA synthesis may predominantly not occur in RA FLSs [22].

In addition to proliferation, apoptosis is another mechanism to control cell numbers in response to DNA damage. It has been shown that significant changes occur in the mitochondrial pathways of apoptosis in RA FLSs, which leads to outstanding resistance to apoptosis. These changes include dysregulation of the Bcl-2 family proteins, which plays a major role in the regulation of the intrinsic pathway of apoptosis $[60,61]$ as well as p53 mutations, that explains the absence of apoptosis due to p53 impairments $[62,63]$. It has been shown that inactivation of the p53 protein by papillomavirus E6 protein in FLSs leads to increased growth rate and inhibited the apoptosis process [64].

Along with the established mechanisms involved in the regulation of apoptosis, it has been determined that

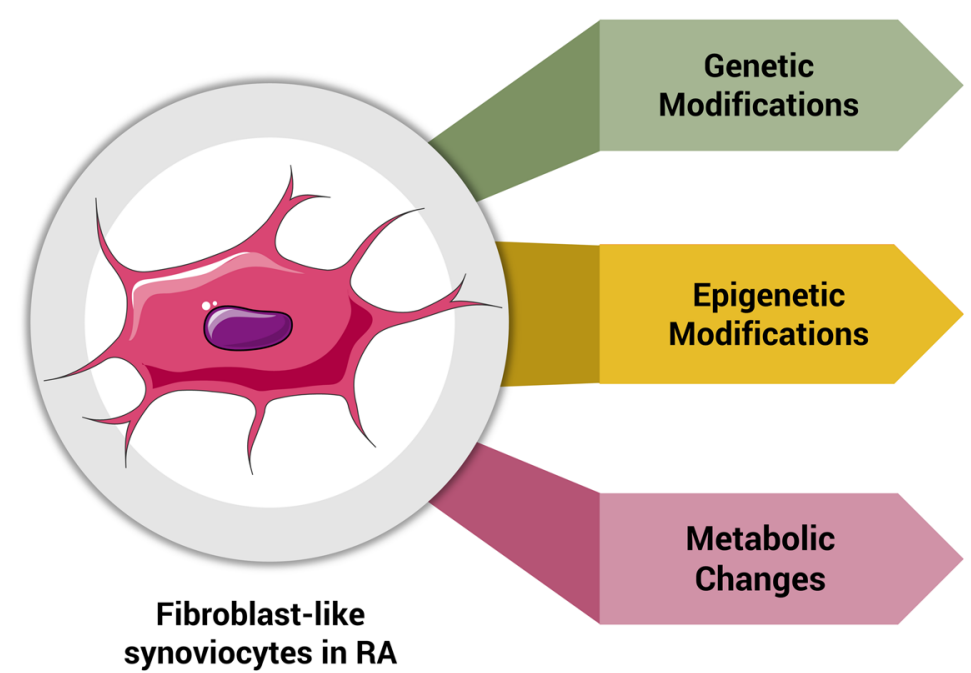

Genetic abnormalities p53 mutations Downregulated p53 expression Upregulated Dyrk1A expression Gain-of-function mutation of BRAF Genetic variations in the cytokine genes

Epigenetic abnormalities

DNA methylation abnormalities Upregulated HDACs

MicroRNA abnormalities LncRNA abnormalities

Higher basal metabolic rate (BMR) Elevated glucose metabolism Elevated choline metabolism Accumulation of metabolic intermediates Elevated anabolic mechanisms

Fig. 2 Increased and chronic glucose metabolism in RA-FLSs due to the presence in hypoxic microenvironment and abundant inflammatory mediators in the inflamed synovium 
the essential glycolytic enzymes can translocate to the nucleus, where they can play an anti-apoptotic role independently of their canonical metabolic role. Hexokinase 2 (HK2), which plays a typical role in the production of glucose 6-phosphate from glucose, can attach to the mitochondrial outer membrane through a transaction with the voltage-dependent anion channel (VDAC) protein [65]. The interaction between HK2 and VDAC prevents the release of pro-apoptotic molecules and inhibits cell apoptosis. Interestingly, there is an overexpression of HK2 in RA FLSs compared to OA FLSs [44].

\section{Dysregulation of angiogenesis in RA FLSs}

Hypoxia is the primary mechanism for promoting the formation and development of new vessels [66, 67]. RA synovial hyperplasia, due to increased oxygen consumption, causes an intensive hypoxic environment. Although the oxygen tension is up to $8 \%$ in healthy conditions, it is less than $1 \%$ in the toxic and highly hypoxic milieu of RA synovium [68]. Hypoxia results in HIF- $\alpha$ activation and overexpression, which induces the transcription of HIFresponsive genes. Among these genes, vascular endothelial growth factor (VEGF), fundamentally participates in synovial angiogenic processes, development of synovitis, and the RA pathogenesis [69].

Other angiogenic growth factors like fibroblast growth factor (FGF) and angiopoietin-2 are also secreted mainly by activated synovial FLSs and MLSs. Furthermore, hypoxia activates glycolytic enzymes like glucose 6-phosphate isomerase (G6PI) as well as glycolysis [70], which subsequently leads to the increased production and secretion of glycolytic intermediate components (like succinate and lactate). These components are potent angiogenic stimulants that play a useful role in sustaining the process of angiogenesis [55, 71]. The angiogenesis, which means the formation of new vessels, has been implicated as one of the fundamental mechanisms in the pathogenesis of several autoimmune diseases including $\mathrm{RA}, \mathrm{OA}$ and spondyloarthropathies. In RA, this process plays a key role in the over-migration and extravasation of the circulating immune cells to the inflammatory and hypertrophic joints and the supply of nutrients and oxygen needed in their toxic environment $[72,73]$.

\section{Migration, invasion, and metastasis of RA FLSs}

In vitro experiments have indicated that RA FLSs play a prominent role in the cartilage tissue destruction, upon being co-cultured with the macrophage line U937. This finding demonstrated that the migration and invasion of FLSs had a fundamental role in the destruction of cartilage and the pannus formation in RA [74]. It has also been further reported that when FLSs isolated from RA patients are transplanted into SCID mice, display aggressive and destructive characteristics in the absence of other immune cells [29]. The initial binding of FLSs to the extracellular matrix components, namely proteoglycans and collagens, results in the activation of signaling pathways involved in their invasive behavior. Subsequently, it has been shown that integrins, particularly the $\beta 1$ family, are overexpressed in RA FLSs. Blocking these integrins on the surface of RA FLSs decreases the binding strength and their invasive capacity [75-77]. Communication and bilateral regulation of integrin activation and cell metabolism is an emerging paradigm. Various metabolic pathways, such as AMP-activated protein kinase (AMPK), mammalian target of rapamycin complex 1 (mTORC1), and HIF- $1 \alpha$ are involved in the regulation of integrins' transcription, function and expression on the cell surface [78, 79]. On the other hand, integrins bilaterally regulate various metabolic pathways by linking to these pathways or directly interacting with metabolic enzymes [80].

Class 3 semaphorins genes, with their inhibitory role in the progression, migration, and invasion of various cancers, were severely reduced in the synovium of RA patients. In particular, semaphorin-3B and semaphorin-3F reduce the migratory and invasive capacity of RA FLSs and suppress the expression of MMPs, thus being proposed as therapeutic targets in suppressing the invasive behavior of RA FLSs [81].

Platelet-derived growth factor (PDGF) levels in the RA synovium and synovial fluid has been plentifully reported [82-84]. In the pathogenesis of RA, PDGF is considered to be an important growth factor and stimulate of production and secretion of the inflammatory mediators of FLSs, in synergistic association with transforming growth factor-beta (TGF- $\beta$ ) $[83,85]$. PDGF is essential for the formation of hypertrophic FLS architecture and the extracellular matrix-degrading invadosome, invasion to cartilage, via activation of several signaling pathways, particularly the PI3K/AKT pathway [86]. Also, the intimal lining has been identified as the primary source of MMPs in RA, and is able to active FLSs with the secretion of collagenases and metalloproteinases, such as MMP-2 and MMP-9, and initiate the destruction of ECM and cartilage [87, 88].

In a recent comprehensive study on the role of different immunological and non-immunological pathways in the behavior of RA FLSs, unexpectedly, the "Huntington's Disease Signaling" pathway and specifically huntingtin-interacting protein-1 (HIP1) was introduced as the regulator of matrix invasion in RA FLSs [89]. Previous studies have also shown that HIP1 is 
associated with cell movement and invasion in cancers $[90,91]$.

\section{Genetic abnormalities involved in FLS cancer-like behavior}

The most critical genetic abnormalities occurred in the context of cancer-like behavior of RA FLSs are those that are also seen in tumors. For example, the p53 tumor suppressor gene has been observed to harbor mutations that contribute to cancerous consequences, including enhanced invasion and proliferation. Inazuka et al. found that there was a p53 mutation with plausible functional modification in four (44.4\%) of the nine RA patients. Moreover, $10 \mathrm{cDNA}$ subclones were identified to harboring ten p53 mutations, in which eight of them were associated with amino acid changes or truncated protein. Functional mutations of p53 were reported in the substitution of Gly at amino acid residue 245 to Asp in two RA patients in three subclones. This mutation was suggested to may functionally affect the FLS, but the evidence was not strongly supportive of the role of p53 mutation in RA [92]. Nonetheless, P53R248Q mutation was reported to downregulate the expression of the pro-apoptotic molecule p53AIP1 in the MH7A RA FLS cell line, resulting in a decreased apoptosis rate and, increasing the tumor-like proliferation of these cells [93]. It seems that p53 mutations are induced by genotoxic exposure randomly, which may be seen in a small number of RA synoviocytes that were present in both erosive and non-erosive areas of the synovium. Moreover, the most important contributing factor for invasive behavior of the cells might be the vicinity of bone and cartilage instead of harboring a p53 mutation [94]. On the other hand, it should be noted that p53 positive cells might not be present in all of the synovial tissues of RA subjects [95]. Nonetheless, several other studies have reported upregulated expression of p53 in RA FLSs [96-98]. In line with these observations, abnormalities were identified in the p53 in RA patients; nonetheless, they were not associated with the cancerous characteristics of the rheumatoid synovium, as evaluated by proliferative manifestations [99].

Except than p53 tumor suppressor gene, other genetic abnormalities have also been reported to be involved in the cancerous behavior of FLSs. Dual-specificity tyrosine-regulated kinase 1A (Dyrk1A), a regulator of the MAPK pathway activation, plays a role in the proliferation and differentiation of mammalian cells. An overexpression of Dyrk1A was observed in the RA synovial tissues as well as in a TNF- $\alpha$-induced FLSs activation model. It was demonstrated that Dyrk1A might increase the cancerous traits of FLSs, including proliferation, migration, and invasion through suppressing the expression of sprouty RTK signaling antagonist 2 (Spry2) and activating the MAPK/ERK signaling pathway in RA [100]. $\mathrm{B}-$ Raf proto-oncogene, serine/threonine kinase (BRAF) is also involved in the regulation of the MAPK/ERK signaling pathway and finally impresses the cell division and differentiation. The V600R gain-of-function mutation of BRAF, which has been associated with several cancers, was also identified in the RA synovial fibroblasts. However, only two of the nine evaluated subjects indicated this mutation. V600R mutation plays a role in the fibroblast transformation, which in turn was involved in the destruction of articular cartilage and bone in RA [101].

Aberrant activation of the sonic hedgehog (SHH) signaling pathway plays a vital role in tumor formation and development. Besides, the SHH signaling pathway through the MAPK/ERK pathway was found to regulate proliferation, migration and tumor-like behavior of RA FLSs [102]. In this regard, it was suggested that targeting the SHH pathway can be considered as an effective therapeutic strategy in RA patients.

Genetic variations in the cytokine genes have also been evaluated with respect to the cancerous behaviors of the RA FLSs. The IL-10 genotype, which is associated with RA progression, did not influence the invasiveness of the RA FLSs when the -2849 non-G carriers were compared to those who were G carriers. However, the adenoviral gene transfer of IL-10 to FLSs resulted in the inhibition of FLS invasiveness [103].

\section{Epigenetic abnormalities involved in cancer-like behavior of FLS}

Epigenetics is characterized as stable and heritable alterations in gene expression without changes in the DNA sequence [104]. Epigenetic modifications (DNA methylation, histone modifications, and non-coding RNAs), modulate gene expression patterns during normal physiological processes and also in response to environmental factors (Table 1). The cellular phenotype and function could be modulated through various epigenetic patterns, named the epigenetic signature. There are many epigenetic modifications in the RA FLSs, which are capable of being involved in RA pathogenesis [105].

\section{DNA methylation abnormalities}

It has been documented that the methylation pattern of the FLS cells is different in RA and OA patients [106]. It is important to notice that DNA methylation and transcription patterns are different in the RA FLS cells isolated from various joints. These findings indicate that there is a complex and joint-specific relationship between gene expression and DNA methylation in modulating joint inflammation at different anatomical locations [107]. Subsequently, investigation on the peripheral blood (PB) lymphocytes in RA patients showed that the genome is 
Table 1 Epigenetic abnormalities of the RA FLS concerning cancer-like behavior

\begin{tabular}{|c|c|c|c|}
\hline Name & Status & Function & References \\
\hline PTPN11 & Hypomethylated & Migration & {$[113]$} \\
\hline LINE1 & Hypomethylated & Aggressiveness & {$[114]$} \\
\hline HDAC 1 and 2 & Upregulated & Apoptosis and proliferation & {$[117]$} \\
\hline miR-10a & Downregulated & Migration, proliferation, invasion & {$[128,129]$} \\
\hline $\operatorname{miR}-27 a$ & Downregulated & Invasion and migration & {$[130,131]$} \\
\hline miR-30a & Downregulated & Autophagy & {$[132]$} \\
\hline $\operatorname{miR}-34 a$ & Downregulated & Apoptosis & {$[133,147]$} \\
\hline miR-15a & Downregulated & Apoptosis & {$[134]$} \\
\hline miR-124a & Downregulated & Proliferation & {$[132]$} \\
\hline miR-155 & Downregulated & The proliferation and invasive behavior & {$[136,139]$} \\
\hline miR-126 & Upregulated & Apoptosis & {$[135]$} \\
\hline miR-221 & Upregulated & Invasion and migration & {$[140]$} \\
\hline miR-663 & Upregulated & Proliferation & {$[141]$} \\
\hline miR-21 & Upregulated & Proliferation & {$[142]$} \\
\hline
\end{tabular}

hyper-methylated. Therefore, the DNA methylation signature of PB-lymphocytes could be considered as a risk indicator [108]. Genes with different methylation pattern in PB-lymphocytes are involved in focal adhesion, cell migration, and extracellular matrix interactions, which resulted in chronic inflammation in RA [109]. Analysis of methylation patterns showed that the differences are seen in integrin, PDGF, and Wnt pathway genes and propose that cell imprinting linked to adhesion, differentiation, and proliferation changes through the disease development [110].

Limb bud and heart development (LBH) deficiency lead to an increase in DNA damage and cell cycle arrest in the S-phase. Furthermore, in vivo, LBH deficiency causes abnormalities in the cell cycle and increases the severity of arthritis in a mouse model [111]. A combination of the differentially methylated loci (DML) with a risk variant regulates the $\mathrm{LBH}$ expression and function, elucidating how epigenetic mechanisms and genetic risk can interact to change cellular function [112]. Tyrosine-Protein phosphatase non-receptor type 11 (PTPN11), encodes the protein tyrosine phosphatase SHP2, showed an elevated expression level in the RA FLSs and played a critical role in the migration of the cells. It has been shown that low expression of SHP2 in the serum transfer mouse model is associated with low disease activity, demonstrating that it could be a potential therapeutic target. Methylation of an intronic enhancer of PTPN11 could increase the expression of SHP2 in the RA FLSs [113].

It has been shown that there is an increased expression (30-300 fold) in long interspersed element 1 (LINE1) in the RA FLSs, compared with the normal FLSs, and its expression is regulated by the DNA methylation mechanism [114]. Investigations on the RA FLS cells propose that LINE1 is associated with the aggressive phenotype of these cells through regulation of stress-activated protein kinase (SAPK) [p38 MAPK] signaling cascades, which is a part of a kinase pathway that leads to the production of cytokines including IL-8, IL-6 [115], and MMPs [116].

\section{Histone modifications}

In histone deacetylase (HDACs) evaluation, two HDACs; HDAC1 and -2 , were upregulated in the RA FLSs compared with the OA FLSs. It has been reported that knockdown of these two HDACs might lead to low proliferation and high apoptosis of the RA FLS cells [117]. Since the RA FLSs have aggressive behavior, like cancer cells, and many investigations have shown benefits from HDAC inhibitors in cancer therapy, these kinds of treatment could be an option in the case of RA. Trichostatin $\mathrm{A}$ is one of the important HDAC inhibitors that has been widely used to inhibit the aggressiveness of the RA FLSs [118]. Studies have illustrated that treatment of the RA FLSs with trichostatin A could decrease invasiveness [113] and inflammatory responses [119] as well as increase apoptosis [113, 120-122]. The low proliferation of the FLSs could be mediated by inhibition of cell-cycle progression, and the high apoptosis could be applied through high expression of pro-apoptotic genes [123]. In vitro studies have shown that combination therapy of SAHA and MS-275, histone deacetylase inhibitors, could prevent the proliferation of the FLSs [124]. Furthermore, HDACs have lots of non-histone targets such as P53, a critical gene in regulating cell proliferation and apoptosis, which is downregulated through HDACs [125]. 
Investigations on animal models of RA have shown that general HDAC inhibitors could decrease disease severity $[124,126,127]$. Furthermore, they have documented that HDACs play a critical role in RA pathogenesis by modifying the FLSs.

\section{MicroRNA abnormalities}

In respect to microRNAs in the RA FLSs, a recent study has shown that there is a different signature of microRNA expression in the RA FLSs compared to the OA FLSs. Of these, the expression of miR-10a in the RA synovial tissue and the FLSs was significantly lower than the OA FLSs. Pro-inflammatory cytokines such as IL-1b and TNF result in decreased expression of miR-10a through the nuclear factor (NF)- $\kappa B$ pathway. This microRNA targets various genes in the TNF/IL1 signaling pathway include BTRC (beta-transducin repeat containing E3 ubiquitinprotein ligase), nuclear receptor subfamily 2 group $C$ member 2 (NR2C2), and interleukin-1 receptor-associated kinase 4 (IRAK4) [128]. Upregulation of miR-10a decreases the expression of $\mathrm{C}-\mathrm{C}$ motif chemokine ligand 2 (CCL2), matrix metallopeptidase (MMP)-1, MMP-13, IL-6, and IL-8 and reduces migration, proliferation, and invasion of the RA FLSs [129]. Another microRNA with a reduced expression profile is miR-27a, which its expression is highly downregulated in FLSs, synovial tissue, and serum of RA patients compared to healthy controls. This study further illustrated that mimic of miR-27a could markedly inhibit invasion and migration of the RA FLSs through downregulating of MMP-2/9/13 and invasionrelated proteins such as RhoA, Rac1, and Cdc42. Furthermore, miR-27a reduce NF-kB p65 and TLR4 protein levels. Another molecule that is regulated by miR-27a is follistatin-like protein 1 (FSTL1), a pro-inflammatory mediator with high expression pattern in RA serum and synovium, especially in patients with positive anticitrullinated protein antibodies (ACPA) [130]. Furthermore, upregulation of miR-27a could increase invasion and migration of the RA FLSs through downregulating the FSTL1, which consequently led to inhibiting of the NF- $\kappa$ B signaling pathway in the RA FLS [131].

A study has shown that the miR-30a expression is reduced in RA patients, compared with healthy controls. Due to miR-30a interactions with Beclin-1, autophagy marker, it was linked to autophagy [132]. Since the miR-34a has been suggested as a regulatory factor for apoptosis, therefore it is linked to the RA FLSs lifespan. Evaluation on miR-34a expression and apoptosis by Niederer et al. has illustrated that the miR-34a targets $\mathrm{X}$-linked inhibitor of apoptosis protein (XIAP). They have documented that there is a negative correlation between high expression of XIAP and low expression of miR-34a in RA FLSs and eventually low expression of miR-34a could lead to apoptosis resistance [133]. In the case of apoptosis, downregulation of miR-15a in the RA FLSs has been reported. Since miR-15a directly targets B cell lymphoma 2 (Bcl-2), which is associated with cell survival, its regulatory role in suppressing Bcl-2 ultimately leads to increased FLS apoptosis in the collagen-induced arthritis (CIA) mice model [134]. Gao et al. have documented that targeting phosphoinositide-3-kinase regulatory subunit 2 (PIK3R2) by miR-126 may modulate apoptosis of the RA FLSs through interfering with the PI3k/AKT signaling pathway [135].

It has been documented that the cyclin-dependent kinase 2 (CDK2) expression could be regulated by the miR-124a, which is associated with MCP-1 secretion and synoviocyte proliferation [132]. Later studies have evaluated the methylation profile of the promoter region of miR-124a in the OA and RA synoviocyte tissue and illustrated that the promoter region in the RA patients was significantly hypermethylated, compared with the OA patients. Hypermethylation of miR-124a might be correlated with its low expression [136], which is correlated to a high proliferation of synoviocytes [137]. Besides, miR-146a can act as a key epigenetic regulator of inflammation in RA, and in regulating the metabolic activity of synovial fibroblasts and their bone destruction [138]. Downregulation of miR-155 in the RA FLSs leads to proliferation and high production of MMP-3. Therefore, overexpression of miR-155 results in decreased MMP-3 production, proliferation and invasive behavior; so, miR155 could be a therapeutic target [136]. Nonetheless, miR-155 has various functions and implicated in many immune regulatory mechanisms such as; $T$ cell-dependent inflammatory responses, $\mathrm{T}$ cell-dependent antibody responses, Treg suppressive functions, B cell development, and activation of tissue macrophages; therefore, it is hard to propose it as a therapeutic marker. One of the validated targets for miR-155 is inositol polyphosphate5-phosphatase D (INPP5D), which has an inhibitory effect on the proliferation of lymphoid and myeloid cells; therefore, the deregulation of miR-155 might lead to fibroblast proliferation and resident myeloid cell infiltration [139]. The analysis showed that the miR-221 silencing could decrease the invasion and migration of the RA FLSs [140].

High expression of miR-663 increases various key disease targets during the RA development and finally leads to the high proliferation of the RA FLSs [141]. Investigations have illustrated that the miR-21 silencing in the RA FLSs is associated with low expression of NF-kB and also the low proliferation rate of the RA FLSs. On the other hand, high expression of miR-21 was linked with the high level of NF- $\mathrm{KB}$ and the elevated level of proliferation in the RA FLSs. Further investigations have illustrated that 
miR-21 through facilitating NF- $\mathrm{kB}$ translocation and affecting the NF- $\kappa B$ pathway could increase the proliferation of the RA FLSs [142].

\section{LncRNA abnormalities}

Long non-coding RNAs (lncRNAs) are RNA molecules containing further than 200 nucleotides in length [143]. lncRNAs play a role in the regulating of genes transcription in several ways, such as RNA sponging, alternative splicing, and epigenetic mechanisms [144]. Aberrant expression of lncRNAs has been reported in FLSs from RA patients and that of healthy individuals that were also involved in clinicopathological manifestations of RA patients [128]. Nonetheless, little has been revealed about the involvement of IncRNAs in the cancerous behaviors of RA FLSs. Ye et al. have reported that the silencing of lncRNA ZFAS1 (which is upregulated in RA FLSs) leads to the reduced migration and invasion in RA FLSs. They have reported that lncRNA ZFAS1 is involved in the migration and invasion of RA FLSs through regulating of miR-27a transcription [145]. Another lncRNA, metastasis-associated lung adenocarcinoma transcript 1 (MALAT1), has been reported to play a role in the apoptosis of RA FLSs via repressing the PI3K/AKT signaling [146]. Hence, lncRNAs are involved in the modulation of genes with the implication in the cancerous behaviors of RA FLSs. Altogether, this is a nascent field of research that needs to be enrichened with comprehensive data to let us come up with the understanding of the decisive implication of lncRNAs in the cancerous behaviors of RA FLSs, for designing future diagnostic tools as well as therapeutic approaches.

\section{Concluding remarks}

Interactions between the structural components of the synovial environment, such as synoviocytes with different cells of immune system, such as T lymphocytes, may play a pivotal role in the ethiopathogenesis of RA disease. Meanwhile, in recent years, FLSs have been introduced as the chief cells involved in the initial onset, the development and spread of synovitis, and, ultimately, the destruction of the adjacent joint and bones. Active and transformed RA FLS at the synovial site, with high proliferation, resistance to apoptosis, invasion, metastatic behavior, and induction of angiogenesis, play a cancerous role in RA pathogenesis. The phenotype and cancer-like behavior of FLSs in RA remind the behavior of CAFs in various neoplasms. This study reviewed the different variations of FLSs that led to their cancer-like behavior (in the metabolism, genetics, and epigenetics areas).

Today, the fundamental role of FLSs in the development of synovial hyperplasia, chronic inflammation, invasion, and articular cartilage destruction has been identified. The metabolic, genetic, and epigenetic alterations involved in the transformation of these cells are also somewhat determined. To better understand the behavior of RA FLS in the inflammatory milieu, further studies are required, focusing on similarities to cells that form the cancerous microenvironment, in particular, CAFs. It is hoped to take a fundamental step toward achieving a targeted and effective therapeutic strategy, with a clear understanding of the behavior of RA FLS and its main contributing factors.

\section{Abbreviations}

ACPA: Anti-citrullinated protein antibodies; AMPK: AMP-activated protein kinase; BCl-2: B cell lymphoma 2; BMR: Basal metabolic rate; BRAF: B-Raf protooncogene, serine/threonine kinase; BrPa: Bromopyruvate; BTRC: Beta-transducin repeat containing E3 ubiquitin-protein ligase; CAFs: Cancer-associated fibroblasts; CCL2: Chemokine ligand 2; CDK2: Cyclin-dependent kinase 2; CK: Choline kinase; CVD: Cardiovascular diseases; DAF: Decay-accelerating factor; DML: Differentially methylated loci; Dyrk1A: Dual-specificity tyrosine-regulated kinase 1A; EAMs: Extra-articular manifestations; FGF: Fibroblast growth factor; FLS: Fibroblast-like synoviocyte; FSTL1: Follistatin-like protein 1; G6PI: Glucose 6-phosphate isomerase; GLUT1: Glucose transporter 1; HDACs: Histone deacetylase; HK2: Hexokinase 2; IHC: Immunohistochemistry; IL: Interleukin; INPP5D: Inositol polyphosphate-5-phosphatase D; IRAK4: Interleukin-1 receptor-associated kinase 4; JAK: Janus kinase; LBH: Limb bud and heart development; LINE1: Long interspersed element 1; InCRNAs: Long non-coding RNAs; MALAT1: Metastasis-associated lung adenocarcinoma transcript 1; MAPK: Mitogen-activated protein kinase; MLS: Macrophage-like synoviocytes; MMP: Matrix metalloproteinases; MMP: Matrix metallopeptidase; mTORC1: Mammalian target of rapamycin complex 1; NF: Nuclear factor; NR2C2: Nuclear receptor subfamily 2 group C member 2; OA: Osteoarthritis; PB: Peripheral blood; PCNA: Proliferating cell nuclear antigen; PDGF: Platelet-derived growth factor; PDGF: Platelet-derived growth factor; PI3K: Phosphatidylinositol3-kinase; PIK3R2: Phosphoinositide-3-kinase regulatory subunit 2; PTPN11: Tyrosine-Protein phosphatase non-receptor type 11; RA: Rheumatoid arthritis; SAPK: Stress-activated protein kinase; SCID: Severe combined immunodeficiency; SF: Synovial fibroblasts; Spry2: Sprouty RTK signaling antagonist 2; TCA:Tricarboxylic acid; TGF- $\beta$ : Transforming growth factor-beta; TNF-a: Tumor necrosis factor-a; UDPGDH: UDP-glucose 6-dehydrogenase; VCAM-1:Vascular cell adhesion molecule-1; VDAC: Voltage-dependent anion channel; VEGF: Vascular endothelial growth factor; XIAP: X-linked inhibitor of apoptosis protein.

\section{Acknowledgements}

Not applicable.

\section{Authors' contributions}

MJA, JK, and SA contributed to acquisition and interpretation of data"and drafting the article. MNT contributed to the conception and design of the study and drafting the article. ASV contributed to acquisition and interpretation of data and revising the article critically for important intellectual content. $\mathrm{AJ}, \mathrm{EF}^{*}$, and $\mathrm{MM}^{*}$ contributed to the conception and design of the study and revising the article critically for important intellectual content. All authors contributed to manuscript revision, read, and approved the submitted version.

\section{Funding}

This research did not receive any specific grant from funding agencies in the public, commercial, or not-for-profit sectors.

Availability of data and materials

Not applicable.

Ethics approval and consent to participate

Not applicable.

Competing interests

The authors declare that there are no conflicts of interest. 


\begin{abstract}
Author details
1 Rheumatology Research Center, Tehran University of Medical Sciences, Tehran, Iran. ${ }^{2}$ Department of Immunology, School of Medicine, Tehran University of Medical Sciences, Tehran, Iran. ${ }^{3}$ Department of Hematology, Faculty of Allied Medicine, Bushehr University of Medical Sciences, Bushehr, Iran. ${ }^{4}$ Department of Immunology, School of Medicine, Iran University of Medical Sciences, Tehran, Iran. ${ }^{5}$ Department of Laboratory Sciences, Khomein University of Medical Sciences, Khomein, Iran. ${ }^{6}$ Joint Reconstruction Reseach Center, Tehran University of Medical Sciences, Tehran, Iran. ${ }^{7}$ Inflammation Research Center, Tehran University of Medical Sciences, Tehran, Iran.
\end{abstract}

Received: 29 July 2020 Accepted: 20 October 2020

Published online: 05 February 2021

\section{References}

1. Scott DL, Wolfe F, Huizinga TW. Rheumatoid arthritis. Lancet. 2010;376(9746):1094-108.

2. Amaya-Amaya J, Botello-Corzo D, Calixto OJ, Calderon-Rojas R, Dominguez AM, Cruz-Tapias P, et al. Usefulness of patientsreported outcomes in rheumatoid arthritis focus group. Arthritis. 2012;2012:935187.

3. Sokka T, Krishnan E, Hakkinen A, Hannonen P. Functional disability in rheumatoid arthritis patients compared with a community population in Finland. Arthritis Rheum. 2003:48(1):59-63.

4. Cadena J, Vinaccia S, Perez A, Rico MI, Hinojosa R, Anaya JM. The impact of disease activity on the quality of life, mental health status, and family dysfunction in colombian patients with rheumatoid arthritis. J Clin Rheumatol. 2003;9(3):142-50.

5. Sokka T, Abelson B, Pincus T. Mortality in rheumatoid arthritis: 2008 update. Clin Exp Rheumatol. 2008;26(5 Suppl 51):35-61.

6. MacGregor AJ, Snieder H, Rigby AS, Koskenvuo M, Kaprio J, Aho K, et al. Characterizing the quantitative genetic contribution to rheumatoid arthritis using data from twins. Arthritis Rheum. 2000:43(1):30-7.

7. Karami J, Aslani S, Jamshidi A, Garshasbi M, Mahmoudi M. Genetic implications in the pathogenesis of rheumatoid arthritis; an updated review. Gene. 2019;9:78.

8. Bang SY, Lee KH, Cho SK, Lee HS, Lee KW, Bae SC. Smoking increases rheumatoid arthritis susceptibility in individuals carrying the HLA-DRB1 shared epitope, regardless of rheumatoid factor or anti-cyclic citrullinated peptide antibody status. Arthritis Rheum. 2010;62(2):369-77.

9. Bartok B, Firestein GS. Fibroblast-like synoviocytes: key effector cells in rheumatoid arthritis. Immunol Rev. 2010;233(1):233-55.

10. Bottini N, Firestein GS. Duality of fibroblast-like synoviocytes in RA: passive responders and imprinted aggressors. Nat Rev Rheumatol. 2013;9(1):24-33

11. Ganesan R, Rasool M. Fibroblast-like synoviocytes-dependent effector molecules as a critical mediator for rheumatoid arthritis: current status and future directions. Int Rev Immunol. 2017;36(1):20-30.

12. McInnes IB, Schett $G$. The pathogenesis of rheumatoid arthritis. N Engl J Med. 2011;365(23):2205-19.

13. Izquierdo E, Canete JD, Celis R, Del Rey MJ, Usategui A, Marsal S, et al. Synovial fibroblast hyperplasia in rheumatoid arthritis: clinicopathologic correlations and partial reversal by anti-tumor necrosis factor therapy. Arthritis Rheum. 2011;63(9):2575-83.

14. Rooney M, Condell D, Quinlan W, Daly L, Whelan A, Feighery C, et al. Analysis of the histologic variation of synovitis in rheumatoid arthritis. Arthritis Rheum. 1988;31(8):956-63.

15. Guo J, Zhao W, Cao X, Yang H, Ding J, Ding J, et al. SIRT1 promotes tumor-like invasion of fibroblast-like synoviocytes in rheumatoid arthritis via targeting TIMP1. Oncotarget. 2017;8(51):88965-73.

16. Liu Y, Pan YF, Xue YQ, Fang LK, Guo XH, Guo X, et al. UPAR promotes tumor-like biologic behaviors of fibroblast-like synoviocytes through PI3K/Akt signaling pathway in patients with rheumatoid arthritis. Cell Mol Immunol. 2018;15(2):171-81.

17. Bhattaram $P$, Jones K. Regulation of fibroblast-like synoviocyte transformation by transcription factors in arthritic diseases. Biochem Pharmacol. 2019;2:345.
18. Liu T, Zhou L, Li D, Andl T, Zhang Y. Cancer-associated fibroblasts build and secure the tumor microenvironment. Front Cell Develop Biol. 2019:7:7.

19. Pap T, Muller-Ladner U, Gay RE, Gay S. Fibroblast biology. Role of synovial fibroblasts in the pathogenesis of rheumatoid arthritis. Arthritis Res. 2000;2(5):361-7

20. Kiener HP, Niederreiter B, Lee DM, Jimenez-Boj E, Smolen JS, Brenner MB. Cadherin 11 promotes invasive behavior of fibroblast-like synoviocytes. Arthritis Rheum. 2009:60(5):1305-10.

21. Lee DM, Kiener HP, Agarwal SK, Noss EH, Watts GF, Chisaka O, et al. Cadherin-11 in synovial lining formation and pathology in arthritis. Science. 2007:315(5814):1006-10.

22. Firestein GS, Kelley WN. Kelley's textbook of rheumatology. Philadelphia: Elsevier/Saunders; 2013.

23. Tran CN, Thacker SG, Louie DM, Oliver J, White PT, Endres JL, et al. Interactions of T cells with fibroblast-like synoviocytes: role of the B7 family costimulatory ligand B7-H3. J Immunol. 2008;180(5):2989-98.

24. Tran CN, Lundy SK, White PT, Endres JL, Motyl CD, Gupta R, et al. Molecular interactions between T cells and fibroblast-like synoviocytes: role of membrane tumor necrosis factor-alpha on cytokine-activated $T$ cells. Am J Pathol. 2007;171(5):1588-98.

25. Yamamura Y, Gupta R, Morita Y, He X, Pai R, Endres J, et al. Effector function of resting $T$ cells: activation of synovial fibroblasts. J Immunol. 2001;166(4):2270-5.

26. Tsai C, Diaz LA Jr, Singer NG, Li LL, Kirsch AH, Mitra R, et al. Responsiveness of human T lymphocytes to bacterial superantigens presented by cultured rheumatoid arthritis synoviocytes. Arthritis Rheum. 1996;39(1):125-36.

27. Shiozawa S, Shiozawa K, Fujita T. Morphologic observations in the early phase of the cartilage-pannus junction. Light and electron microscopic studies of active cellular pannus. Arthritis Rheum. 1983;26(4):472-8.

28. Firestein GS. Invasive fibroblast-like synoviocytes in rheumatoid arthritis. Passive responders or transformed aggressors? Arthritis Rheum. 1996;39(11):1781-90.

29. Muller-Ladner U, Kriegsmann J, Franklin BN, Matsumoto S, Geiler T, Gay $\mathrm{RE}$, et al. Synovial fibroblasts of patients with rheumatoid arthritis attach to and invade normal human cartilage when engrafted into SCID mice. Am J Pathol. 1996;149(5):1607-15.

30. Ai R, Whitaker JW, Boyle DL, Tak PP, Gerlag DM, Wang W, et al. DNA Methylome Signature in Synoviocytes From Patients With Early Rheumatoid Arthritis Compared to Synoviocytes From Patients With Longstanding Rheumatoid Arthritis. Arthritis Rheumatol. 2015;67(7):1978-80.

31. Lefevre S, Knedla A, Tennie C, Kampmann A, Wunrau C, Dinser R, et al. Synovial fibroblasts spread rheumatoid arthritis to unaffected joints. Nat Med. 2009;15(12):1414-20.

32. Smolen JS, Aletaha D, Barton A, Burmester GR, Emery P, Firestein GS, et al. Rheumatoid arthritis. Nat Rev Dis Primers. 2018:4:18001.

33. Ramsay EE, Hogg PJ, Dilda PJ. Mitochondrial metabolism inhibitors for cancer therapy. Pharm Res. 2011;28(11):2731-44.

34. Maclver NJ, Michalek RD, Rathmell JC. Metabolic regulation of T lymphocytes. Annu Rev Immunol. 2013;31:259-83.

35. Ghesquiere B, Wong BW, Kuchnio A, Carmeliet P. Metabolism of stromal and immune cells in health and disease Nature. 2014;511(7508):167-76

36. Yin Y, Choi SC, Xu Z, Perry DJ, Seay H, Croker BP, et al. Normalization of CD4 + T cell metabolism reverses lupus. Sci Transl Med. 2015;7(274):274ra18.

37. McDonald G, Deepak S, Miguel L, Hall CJ, Isenberg DA, Magee Al, et al. Normalizing glycosphingolipids restores function in CD4 + T cells from lupus patients. J Clin Invest. 2014;124(2):712-24.

38. Metsios GS, Stavropoulos-Kalinoglou A, Nevill AM, Douglas KM, Koutedakis Y, Kitas GDJ. Cigarette smoking significantly increases basal metabolic rate in patients with rheumatoid arthritis. Gene. 2008:67(1):70-3.

39. Rall L, Roubenoff R. Rheumatoid cachexia: metabolic abnormalities, mechanisms and interventions. Rheumatology. 2004:43(10):1219-23.

40. Guma M, Tiziani S, Firestein GS. Metabolomics in rheumatic diseases: desperately seeking biomarkers. Nat Rev Rheumatol. 2016;12(5):269-81.

41. Bustamante MF, Garcia-Carbonell R, Whisenant KD, Guma M. Fibroblastlike synoviocyte metabolism in the pathogenesis of rheumatoid arthritis. Arthritis Res Ther. 2017:19(1):110. 
42. Ahn JK, Kim S, Hwang J, Kim J, Kim KH, Cha HS. GC/TOF-MS-based metabolomic profiling in cultured fibroblast-like synoviocytes from rheumatoid arthritis. Joint Bone Spine. 2016;83(6):707-13.

43. Kim S, Hwang J, Xuan J, Jung YH, Cha H-S, Kim KH. Global metabolite profiling of synovial fluid for the specific diagnosis of rheumatoid arthritis from other inflammatory arthritis. PLoS One. 2014;9(6):e97501.

44. Garcia-Carbonell R, Divakaruni AS, Lodi A, Vicente-Suarez I, Saha A, Cheroutre H, et al. Critical Role of Glucose Metabolism in Rheumatoid Arthritis Fibroblast-like Synoviocytes. Arthritis Rheumatol. 2016;68(7):1614-26

45. Volchenkov R, Dung Cao M, Elgstoen KB, Goll GL, Eikvar K, Bjorneboe O, et al. Metabolic profiling of synovial tissue shows altered glucose and choline metabolism in rheumatoid arthritis samples. Scand J Rheumatol. 2017:46(2):160-1.

46. Ahn JK, Kim S, Hwang J, Kim J, Kim KH, Cha H-S. GC/TOF-MS-based metabolomic profiling in cultured fibroblast-like synoviocytes from rheumatoid arthritis. Joint Bone Spine. 2016;83(6):707-13.

47. Guma M, Sanchez-Lopez E, Lodi A, Garcia-Carbonell R, Tiziani S, Karin M, et al. Choline kinase inhibition in rheumatoid arthritis. Ann Rheum Dis 2015;74(7):1399-407.

48. Matsui T, Nakata N, Nagai S, Nakatani A, Takahashi M, Momose T, et al. Inflammatory cytokines and hypoxia contribute to 18F-FDG uptake by cells involved in pannus formation in rheumatoid arthritis. J Nucl Med. 2009;50(6):920-6.

49. de Oliveira PG, Farinon M, Sanchez-Lopez E, Miyamoto S, Guma M. Fibroblast-like synoviocytes glucose metabolism as a therapeutic target in rheumatoid arthritis. Front Immunol. 2019:10:1743.

50. Young SP, Kapoor SR, Viant MR, Byrne JJ, Filer A, Buckley CD, et al. The impact of inflammation on metabolomic profiles in patients with arthritis. Arthr Rhuem. 2013;65(8):2015-23.

51. Jiang $M$, Chen $T$, Feng $H$, Zhang $Y$, Li L, Zhao A, et al. Serum metabolic signatures of four types of human arthritis. J Proteome Res. 2013;12(8):3769-79

52. de Molina AR, Gallego-Ortega D, Sarmentero-Estrada J, Lagares D, del

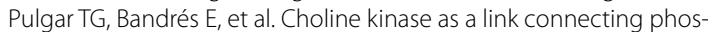
pholipid metabolism and cell cycle regulation: Implications in cancer therapy. Int J Biochem Cell Biol. 2008;40(9):1753-63.

53. Glunde K, Bhujwalla ZM, Ronen SM. Choline metabolism in malignant transformation. Nat Rev Cancer. 2011;11(12):835.

54. de Molina AR, Bánez-Coronel M, Gutiérrez R, Rodríguez-González A Olmeda D, Megías D, et al. Choline kinase activation is a critical requirement for the proliferation of primary human mammary epithelial cells and breast tumor progression. Cancer Res. 2004;64(18):6732-9.

55. Biniecka M, Canavan M, McGarry T, Gao W, McCormick J, Cregan S, et al. Dysregulated bioenergetics: a key regulator of joint inflammation. Ann Rheum Dis. 2016;75(12):2192-200.

56. Mills $E_{,} O^{\prime}$ Neill LA. Succinate: a metabolic signal in inflammation. Trends Cell Biol. 2014;24(5):313-20.

57. Zhu H, Chen L, Zhou W, Huang Z, Hu J, Dai S, et al. Over-expression of the ATP5J gene correlates with cell migration and 5-fluorouracil sensitivity in colorectal cancer. PloS one. 2013;8(10):e76846.

58. Cojocaru M, Cojocaru IM, Silosi I, Vrabie CDJM. Metabolic syndrome in rheumatoid arthritis. Mediators Inflamm. 2012;7(2):148.

59. Matsuo Y, Mizoguchi F, Saito T, Kawahata K, Ueha S, Matsushima K, et al. Local fibroblast proliferation but not influx is responsible for synovial hyperplasia in a murine model of rheumatoid arthritis. Biochem Biophys Res Commun. 2016;470(3):504-9.

60. Matsumoto S, Muller-Ladner U, Gay RE, Nishioka K, Gay S. Ultrastructural demonstration of apoptosis, Fas and BCl-2 expression of rheumatoid synovial fibroblasts. J Rhuematol. 1996;23(8):1345-52.

61. Lee SY, Kwok SK, Son HJ, Ryu JG, Kim EK, Oh HJ, et al. IL-17-mediated $\mathrm{BCl}-2$ expression regulates survival of fibroblast-like synoviocytes in rheumatoid arthritis through STAT3 activation. Arthritis Res Ther. 2013;15(1):R31.

62. Cha HS, Rosengren S, Boyle DL, Firestein GS. PUMA regulation and proapoptotic effects in fibroblast-like synoviocytes. Arthritis Rheum. 2006;54(2):587-92.

63. You X, Boyle DL, Hammaker D, Firestein GS. PUMA-mediated apoptosis in fibroblast-like synoviocytes does not require p53. Arthritis Res Ther. 2006;8(6):R157.
64. Aupperle KR, Boyle DL, Hendrix M, Seftor EA, Zvaifler NJ, Barbosa M, et al. Regulation of synoviocyte proliferation, apoptosis, and invasion by the p53 tumor suppressor gene. Am J Pathol. 1998;152(4):1091-8.

65. Yu X, Li S. Non-metabolic functions of glycolytic enzymes in tumorigenesis. Oncogene. 2017;36(19):2629-36.

66. Tas SW, Maracle CX, Balogh E, Szekanecz Z. Targeting of proangiogenic signalling pathways in chronic inflammation. Nat Rev Rheumatol. 2016;12(2):111-22.

67. Del Rey MJ, Izquierdo E, Usategui A, Gonzalo E, Blanco FJ, Acquadro F, et al. The transcriptional response of normal and rheumatoid arthritis synovial fibroblasts to hypoxia. Arthritis Rheum. 2010;62(12):3584-94.

68. Biniecka M, Fox E, Gao W, Ng CT, Veale DJ, Fearon U, et al. Hypoxia induces mitochondrial mutagenesis dysfunction in inflammatory arthritis. 2011;63(8):2172-82.

69. Veale DJ, Fearon U. Inhibition of angiogenic pathways in rheumatoid arthritis: potential for therapeutic targeting. Best Pract Res Clin Rheumatol. 2006;20(5):941-7.

70. Lu Y, Yu SS, Zong M, Fan SS, Lu TB, Gong RH, et al. Glucose-6-Phosphate Isomerase (G6PI) Mediates Hypoxia-Induced Angiogenesis in Rheumatoid Arthritis. Sci Rep. 2017:7:40274.

71. Sapieha P, Sirinyan M, Hamel D, Zaniolo K, Joyal JS, Cho JH, et al. The succinate receptor GPR91 in neurons has a major role in retinal angiogenesis. Nat Med. 2008;14(10):1067-76.

72. MacDonald IJ, Liu SC, Su CM, Wang YH, Tsai CH, Tang CH. Implications of angiogenesis involvement in arthritis. Int J Mol Sci. 2018;19:7.

73. Elshabrawy HA, Chen Z, Volin MV, Ravella S, Virupannavar S, Shahrara S. The pathogenic role of angiogenesis in rheumatoid arthritis. Angiogenesis. 2015;18(4):433-48.

74. Scott BB, Weisbrot LM, Greenwood JD, Bogoch ER, Paige CJ, Keystone EC. Rheumatoid arthritis synovial fibroblast and U937 macrophage/ monocyte cell line interaction in cartilage degradation. Arthritis Rheum. 1997;40(3):490-8

75. Peters MA, Wendholt D, Strietholt S, Frank S, Pundt N, Korb-Pap A, et al. The loss of alpha2beta1 integrin suppresses joint inflammation and cartilage destruction in mouse models of rheumatoid arthritis. Arthritis Rheum. 2012;64(5):1359-68.

76. Morales-Ducret J, Wayner E, Elices MJ, Alvaro-Gracia JM, Zvaifler NJ, Firestein GS. Alpha 4/beta 1 integrin (VLA-4) ligands in arthritis. Vascular cell adhesion molecule-1 expression in synovium and on fibroblast-like synoviocytes. J Immunol. 1992;149(4):1424-31.

77. McInnes IB, Leung BP, Liew FY. Cell-cell interactions in synovitis. Interactions between T lymphocytes and synovial cells. Arthritis Res. 2000;2(5):374-8.

78. Ata R, Antonescu CN. Integrins and cell metabolism: an intimate relationship impacting cancer. Int J Mol Sci. 2017;18:1.

79. Suto T, Karonitsch T. The immunobiology of mTOR in autoimmunity. J Autoimmun. 2020;110:102373.

80. Cantor JM, Ginsberg MH. CD98 at the crossroads of adaptive immunity and cancer. J Cell Sci. 2012;125(Pt 6):1373-82.

81. Tang MW, Malvar Fernandez B, Newsom SP, van Buul JD, Radstake T, Baeten DL, et al. Class 3 semaphorins modulate the invasive capacity of rheumatoid arthritis fibroblast-like synoviocytes. Rheumatology. 2018;57(5):909-20.

82. Remmers EF, Sano H, Wilder RL. Platelet-derived growth factors and heparin-binding (fibroblast) growth factors in the synovial tissue pathology of rheumatoid arthritis. Semin Arthritis Rheum. 1991:21(3):191-9.

83. Shibuya H, Yoshitomi H, Murata K, Kobayashi S, Furu M, Ishikawa M, et al. TNFalpha, PDGF, and TGFbeta synergistically induce synovial lining hyperplasia via inducible PI3Kdelta. Mod Rheumatol. 2015;25(1):72-8.

84. Thornton SC, Por SB, Penny R, Richter M, Shelley L, Breit SN. Identification of the major fibroblast growth factors released spontaneously in inflammatory arthritis as platelet derived growth factor and tumour necrosis factor-alpha. Clin Exp Immunol. 1991:86(1):79-86.

85. Rosengren S, Corr M, Boyle DL. Platelet-derived growth factor and transforming growth factor beta synergistically potentiate inflammatory mediator synthesis by fibroblast-like synoviocytes. Arthritis Res Ther. 2010;12(2):R65.

86. Lauzier A, Lavoie RR, Charbonneau M, Gouin-Boisvert B, Harper K, Dubois CM. Snail Is a Critical Mediator of Invadosome Formation and Joint Degradation in Arthritis. Am J Pathol. 2016;186(2):359-74. 
87. Laragione T, Brenner M, Li W, Gulko PS. Cia5d regulates a new fibroblastlike synoviocyte invasion-associated gene expression signature. Arthritis Res Ther. 2008;10(4):R92.

88. Xue SN, Lei J, Lin DZ, Yang C, Yan L. Changes in biological behaviors of rat dermal fibroblasts induced by high expression of MMP9. World J Emerg Med. 2014;5(2):139-43.

89. Ai R, Laragione T, Hammaker D, Boyle DL, Wildberg A, Maeshima K, et al. Comprehensive epigenetic landscape of rheumatoid arthritis fibroblast-like synoviocytes. Nat Commun. 2018;9(1):1921.

90. Li D, Chen F, Ding J, Lin N, Li Z, Wang X. Knockdown of HIP1 expression promotes ligand-induced endocytosis of EGFR in HeLa cells. Oncol Rep. 2017;38(6):3387-91.

91. Wang J, Yu M, Guo Q, Ma Q, Hu C, Ma Z, et al. Prognostic significance of huntingtin interacting protein 1 expression on patients with acute myeloid leukemia. Sci Rep. 2017;7:45960.

92. Wang J, Yu M, Guo Q, Ma Q, Hu C, Ma Z, et al. Prognostic significance of huntingtin interacting protein 1 expression on patients with acute myeloid leukemia. Sci Rep. 2017;7:45960.

93. Igarashi $\mathrm{H}$, Hirano H, Yahagi A, Saika T, Ishihara KJCI. Anti-apoptotic roles for the mutant p53R248Q through suppression of p53-regulated apoptosis-inducing protein 1 in the RA-derived fibroblast-like synoviocyte cell line MH7A. Resist. 2014;150(1):12-21.

94. Yamanishi Y, Boyle DL, Green DR, Keystone EC, Connor A, Zollman S, et al. p53 tumor suppressor gene mutations in fibroblast-like synoviocytes from erosion synovium and non-erosion synovium in rheumatoid arthritis. Gene. 2004;7(1):R12.

95. Lee YH, Ji JD, Kim A, Kim CH, Song GGJTKjoim. Expression of p53 protein in rheumatoid arthritis synovium. An immunohistochemical analysis. 1999;14(1):59.

96. Firestein GS, Nguyen K, Aupperle KR, Yeo M, Boyle DL, Zvaifler NJ. Apoptosis in rheumatoid arthritis: p53 overexpression in rheumatoid arthritis synovium. Am J Pathol. 1996;149(6):2143.

97. Xiao P, Hao Y, Zhu X, Wu X. p53 contributes to quercetin-induced apoptosis in human rheumatoid arthritis fibroblast-like synoviocytes. Inflammation. 2013:36(2):272-8.

98. Zhang T, Li H, Shi J, Li S, Li M, Zhang L, et al. p53 predominantly regulates IL-6 production and suppresses synovial inflammation in fibroblast-like synoviocytes and adjuvant-induced arthritis. Arthritis research therapy. 2016;18(1):271.

99. Rème T, Travaglio A, Gueydon E, Adla L, Jorgensen C, Sany JJC, et al. Mutations of the p53 tumour suppressor gene in erosive rheumatoid synovial tissue. Gene 1998;111(2):353.

100. Guo X, Zhang D, Zhang X, Jiang J, Xue P, Wu C, et al. Dyrk1 A promotes the proliferation, migration and invasion of fibroblast-like synoviocytes in rheumatoid arthritis via down-regulating Spry 2 and activating the ERK MAPK pathway. 2018;55:63-70.

101. Weisbart RH, Chan G, Heinze E, Mory R, Nishimura RN, Colburn KJJoBC BRAF drives synovial fibroblast transformation in rheumatoid arthritis. 2010;285(45):34299-303.

102. Liu F, Feng $X X$, Zhu SL, Huang HY, Chen YD, Pan YF, et al. Sonic Hedgehog Signaling Pathway Mediates Proliferation and Migration of Fibroblast-Like Synoviocytes in Rheumatoid Arthritis via MAPK/ERK Signaling Pathway. Front Immunol. 2018;9:2847.

103. Lard L, Van Gaalen F, Schonkeren J, Pieterman E, Stoeken G, Vos K, et al. Association of the-2849 interleukin-10 promoter polymorphism with autoantibody production and joint destruction in rheumatoid arthritis. 2003;48(7):1841-8.

104. Aslani S, Mahmoudi M, Karami J, Jamshidi AR, Malekshahi Z, Nicknam $\mathrm{MH}$. Epigenetic alterations underlying autoimmune diseases. Autoimmunity. 2016:49(2):69-83.

105. Karami J, Aslani S, Tahmasebi MN, Mousavi MJ, Sherafat Vaziri A, Jamshidi A, et al. Epigenetics in rheumatoid arthritis; fibroblast-like synoviocytes as an emerging paradigm in the disease pathogenesis. Immunology and Cell Biology. 2019.

106. Nakano K, Whitaker JW, Boyle DL, Wang W, Firestein GS. DNA methylome signature in rheumatoid arthritis. Ann Rheum Dis. 2013;72(1):110-7.

107. Frank-Bertoncelj M, Trenkmann M, Klein K, Karouzakis E, Rehrauer $\mathrm{H}$, Bratus A, et al. Epigenetically-driven anatomical diversity of synovial fibroblasts guides joint-specific fibroblast functions. Nat Commun. 2017:8:14852.
108. Rhead B, Holingue C, Cole M, Shao X, Quach HL, Quach D, et al. Rheumatoid Arthritis Naive T Cells Share Hypermethylation Sites With Synoviocytes. Arthritis Rheumatol. 2017:69(3):550-9.

109. Bottini N, Firestein GS. Duality of fibroblast-like synoviocytes in RA: passive responders and imprinted aggressors. Nat Rev Rheumatol. 2013;9(1):24.

110. Ai R, Whitaker JW, Boyle DL, Tak PP, Gerlag DM, Wang W, et al. DNA methylome signature in synoviocytes from patients with early rheumatoid arthritis compared to synoviocytes from patients with longstanding rheumatoid arthritis. Arthritis rheumatology. 2015;67(7):1978-80.

111. Matsuda S, Hammaker D, Topolewski K, Briegel KJ, Boyle DL, Dowdy $\mathrm{S}$, et al. Regulation of the cell cycle and inflammatory arthritis by the transcription cofactor LBH gene. The Journal of Immunology. 2017:ji1700719.

112. Hammaker D, Whitaker JW, Maeshima K, Boyle DL, Ekwall AKH, Wang W, et al. LBH gene transcription regulation by the interplay of an enhancer risk allele and DNA methylation in rheumatoid arthritis. Arthritis Rheumatology. 2016;68(11):2637-45.

113. Maeshima K, Stanford SM, Hammaker D, Sacchetti C, Zeng L-F, Ai R, et al. Abnormal PTPN1 1 enhancer methylation promotes rheumatoid arthritis fibroblast-like synoviocyte aggressiveness and joint inflammation. JCl Insight. 2016;1:7.

114. Neidhart M, Rethage J, Kuchen S, Künzler P, Crowl RM, Billingham ME, et al. Retrotransposable L1 elements expressed in rheumatoid arthritis synovial tissue: association with genomic DNA hypomethylation and influence on gene expression. Arthr Rhuem. 2000;43(12):2634-47.

115. Suzuki M, Tetsuka T, Yoshida S, Watanabe N, Kobayashi M, Matsui N, et al. The role of p38 mitogen-activated protein kinase in IL-6 and IL-8 production from the TNF-a-or IL-1 $\beta$-stimulated rheumatoid synovial fibroblasts. FEBS Lett. 2000;465(1):23-7.

116. Ravanti L, Heino J, López-Otín C, Kähäri V-M. Induction of collagenase-3 (MMP-13) expression in human skin fibroblasts by three-dimensional collagen is mediated by p38 mitogen-activated protein kinase. J Biol Chem. 1999;274(4):2446-55.

117. Horiuchi M, Morinobu A, Chin T, Sakai Y, Kurosaka M, Kumagai S. Expression and function of histone deacetylases in rheumatoid arthritis synovial fibroblasts. J Rhuematol. 2009;36(8):1580-9.

118. Glozak M, Seto E. Histone deacetylases and cancer. Oncogene. 2007;26(37):5420

119. Grabiec AM, Korchynskyi O, Tak PP, Reedquist KA. Histone deacetylase inhibitors suppress rheumatoid arthritis fibroblast-like synoviocyte and macrophage IL-6 production by accelerating mRNA decay. Ann Rheum Dis. 2012;71(3):424-31.

120. Jüngel A, Baresova V, Ospelt C, Simmen BR, Michel BA, Gay RE, et al. Trichostatin A sensitises rheumatoid arthritis synovial fibroblasts for TRAIL-induced apoptosis. Ann Rheum Dis. 2006;65(7):910-2.

121. Morinobu A, Wang B, Liu J, Yoshiya S, Kurosaka M, Kumagai S. Trichostatin A cooperates with Fas-mediated signal to induce apoptosis in rheumatoid arthritis synovial fibroblasts. J Rhuematol. 2006;33(6):1052-60.

122. Nakamura C, Matsushita I, Kosaka E, Kondo T, Kimura T. Anti-arthritic effects of combined treatment with histone deacetylase inhibitor and low-intensity ultrasound in the presence of microbubbles in human rheumatoid synovial cells. Rheumatology. 2008:47(4):418-24.

123. Bolden JE, Peart MJ, Johnstone RW. Anticancer activities of histone deacetylase inhibitors. Nat Rev Drug Discov. 2006:5(9):769.

124. Joosten LA, Leoni F, Meghji S, Mascagni P. Inhibition of HDAC activity by ITF2357 ameliorates joint inflammation and prevents cartilage and bone destruction in experimental arthritis. Molecular medicine. 2011;17(5-6):391-6.

125. Juan L-J, Shia W-J, Chen M-H, Yang W-M, Seto E, Lin Y-S, et al. Histone deacetylases specifically down-regulate p53-dependent gene activation. J Biol Chem. 2000;275(27):20436-43.

126. Nasu Y, Nishida K, Miyazawa S, Komiyama T, Kadota Y, Abe N, et al. Trichostatin A, a histone deacetylase inhibitor, suppresses synovial inflammation and subsequent cartilage destruction in a collagen antibody-induced arthritis mouse model. Osteoarthritis Cartilage. 2008;16(6):723-32.

127. Lin HS, Hu CY, Chan HY, Liew YY, Huang HP, Lepescheux L, et al. Anti-rheumatic activities of histone deacetylase (HDAC) inhibitors in vivo in collagen-induced arthritis in rodents. Br J Pharmacol. 2007;150(7):862-72. 
128. Mu N, Gu J, Huang T, Zhang C, Shu Z, Li M, et al. A novel NF-kB/ YY1/microRNA-10a regulatory circuit in fibroblast-like synoviocytes regulates inflammation in rheumatoid arthritis. Scientific reports. 2016;6:20059.

129. Hussain N, Zhu W, Jiang C, Xu J, Wu X, Geng M, et al. Down-regulation of miR-10a-5p in synoviocytes contributes to TBX5-controlled joint inflammation. J Cell Mol Med. 2018;22(1):241-50.

130. Li D, Wang Y, Xu N, Wei Q, Wu M, Li X, et al. Follistatin-like protein 1 is elevated in systemic autoimmune diseases and correlated with disease activity in patients with rheumatoid arthritis. Arthritis research therapy. 2011;13(1):R17.

131. Hong W, Zhang P, Wang X, Tu J, Wei W. The Effects of MicroRNAs on Key Signalling Pathways and Epigenetic Modification in FibroblastLike Synoviocytes of Rheumatoid Arthritis. Mediators of inflammation. 2018;2018.

132. Salehi E, Eftekhari R, Oraei M, Gharib A, Bidad K. MicroRNAs in rheumatoid arthritis. Clin Rheumatol. 2015;34(4):615-28.

133. Niederer F, Trenkmann M, Ospelt C, Karouzakis E, Neidhart M, Stanczyk J, et al. Down-regulation of microRNA-34a* in rheumatoid arthritis synovial fibroblasts promotes apoptosis resistance. Arthr Rhuem. 2012;64(6):1771-9.

134. Vicente R, Noël D, Pers Y-M, Apparailly F, Jorgensen C. Deregulation and therapeutic potential of microRNAs in arthritic diseases. Nat Rev Rheumatol. 2016;12(4):211.

135. Gao J, Zhou X-L, Kong R-N, Ji L-M, He L-L, Zhao D-B. microRNA-126 targeting PIK3R2 promotes rheumatoid arthritis synovial fibro-blasts proliferation and resistance to apoptosis by regulating PI3K/AKT pathway. Exp Mol Pathol. 2016;100(1):192-8.

136. Zhou Q, Long L, Shi G, Zhang J, Wu T, Zhou B. Research of the methylation status of miR-124a gene promoter among rheumatoid arthritis patients. Clinical and Developmental Immunology. 2013;2013.

137. Singh RP, Massachi I, Manickavel S, Singh S, Rao NP, Hasan S, et al. The role of miRNA in inflammation and autoimmunity. Autoimmun rev. 2013;12(12):1160-5.

138. Saferding V, Puchner A, Goncalves-Alves E, Hofmann M, Bonelli M, Brunner JS, et al. MicroRNA-146a governs fibroblast activation and joint pathology in arthritis. J Autoimmun. 2017:82:74-84.
139. Chen X-M, Huang Q-C, Yang S-L, Chu Y-L, Yan Y-H, Han L, et al. Role of micro RNAs in the pathogenesis of rheumatoid arthritis: novel perspectives based on review of the literature. Medicine. 2015;94(31).

140. Yang S, Yang Y. Downregulation of microRNA-221 decreases migration and invasion in fibroblast-like synoviocytes in rheumatoid arthritis. Mol Med Rep. 2015;12(2):2395-401.

141. Miao C-g, Shi W-j, Xiong Y-y, Yu H, Zhang X-I, Qin M-s, et al. MicroRNA-663 activates the canonical Wnt signaling through the adenomatous polyposis coli suppression. Immunology letters. 2015;166(1):45-54

142. Chen Y, Xian P-F, Yang L, Wang S-X. MicroRNA-21 promotes proliferation of fibroblast-like synoviocytes through mediation of NF-KB nuclear translocation in a rat model of collagen-induced rheumatoid arthritis. BioMed research international. 2016;2016.

143. Shi X, Sun M, Liu H, Yao Y, Song YJCl. Long non-coding RNAs: a new frontier in the study of human diseases. 2013;339(2):159-66.

144. Mercer TR, Dinger ME, Mattick JSJNrg. Long non-coding RNAs: insights into functions. 2009;10(3):155.

145. Ye Y, Gao X, Yang N. LncRNA ZFAS1 promotes cell migration and invasion of fibroblast-like synoviocytes by suppression of miR-27a in rheumatoid arthritis. Hum Cell. 2018:31(1):14-21.

146. Pan F, Zhu L, Lv H, Pei C. Quercetin promotes the apoptosis of fibroblast-like synoviocytes in rheumatoid arthritis by upregulating IncRNA MALAT1. Int J Mol Med. 2016;38(5):1507-14.

147. Miao C-g, Yang Y-y, He X, Xu T, Huang C, Huang Y, et al. New advances of microRNAs in the pathogenesis of rheumatoid arthritis, with a focus on the crosstalk between DNA methylation and the microRNA machinery. Cellular signalling. 2013;25(5):1118-25.

\section{Publisher's note}

Springer Nature remains neutral with regard to jurisdictional claims in published maps and institutional affiliations.
Ready to submit your research? Choose BMC and benefit from:

- fast, convenient online submission

- thorough peer review by experienced researchers in your field

- rapid publication on acceptance

- support for research data, including large and complex data types

- gold Open Access which fosters wider collaboration and increased citations

- maximum visibility for your research: over $100 \mathrm{M}$ website views per year

At $\mathrm{BMC}$, research is always in progress.

Learn more biomedcentral.com/submissions 